\title{
Interpreting subdivision in a malocclusion Angle's classification system among orthodontics
}

\author{
Masrina Mohammad Yasim*, Ida Ayu Evangelina*, Iwa Rahmat Sunaryo* \\ *Department of Orthodontics Faculty of Dentistry Universitas Padjadjaran
}

\begin{abstract}
Introduction: Angle's method still seems to be the most popular tool for classification of malocclusion. Confusion arises in the community of Orthodontic regarding the classification and interpretation of subdivision malocclusion in Angle's classification system. The purpose of this study was to survey orthodontists in West Java to determine their consistency in classifying subdivision malocclusion and their viewpoints on the meaning of subdivision. Methods: The type of research was descriptive with survey method by using questionnaire. The study uses total sampling technique with some inclusion criteria. Data obtained were analyzed and presented in table form. Results: Of the 80 respondents, $71.3 \%$ is consistent, $22.5 \%$ is doubtful and $6.6 \%$ is inconsistent in classifying subdivision malocclusion. 37 respondents (46.25\%) believe that subdivision refers to the Class II side, 20 respondents (25\%) believe it refers to the Class I side 4 respondents (5\%) says subdivision refers to neither Class I nor Class II side and 19 respondents $(23.75 \%)$ says that subdivision referred to both side. Conclusion: Most of orthodontists are consistent in classifying subdivision malocclusion, majority of the responded orthodontists stated that subdivision refers to the abnormal side of the arches and most of the responded orthodontist use Proffit and Common usage as their source of reference.
\end{abstract}

Keywords: Angle's classification, subdivision.

\section{INTRODUCTION}

Malocclusion is deviation from the ideal occlusion that may be considered aesthetically unsatisfactory thus implying a condition of imbalance in the relative sizes and position of teeth, facial bones and soft tissues (lips, cheek, and tongue). ${ }^{1}$ Edward $\mathrm{H}$. Angle developed an anteroposterior malocclusion classification system in 1899 which is still extensively utilized in orthodontic practice to this day. ${ }^{2}$ Classification is an important communication tool between dental school lecturers and students and between practitioners. ${ }^{3,4}$
Angle divided malocclusions into three broad classes: Class I (neutroclusion), Class II (distoclusion) and Class III (mesioclusion). He further draws his classifications by separating them into division and subdivision. Angle does not fully or clearly explain the definition of a subdivision malocclusion. Confusion exists regarding the meaning of subdivision that resulted in a disparity when classifying unilateral malocclusion. ${ }^{5}$ Subdivision is the occurrence of a unilateral malocclusion. ${ }^{6,7,8,9}$

In a recent study by Siegel, 34 chairpersons of United States Orthodontic Departments were surveyed as to their understanding of Class II subdivision. ${ }^{5} 22$ 
respondents believe that subdivision referred to the Class II side, 8 believed it referred to the Class I side, and 3 teach neither meaning of subdivision. From the responses received, fewer than 65\% of orthodontic educators agree on the meaning of subdivision. Some orthodontists believe that subdivision refers to an asymmetrical occlusion with a Class II or Class III molar relationship on the left side and a Class I molar relationship on the right side. Other orthodontists perceive just the opposite.

This illustrates the basic confusion in classifying malocclusions. The purpose of this study was to survey orthodontists in West Java to determine their consistency in classifying subdivision malocclusion and their viewpoints on the meaning of subdivision.

\section{METHODS}

This study is descriptive study using crosssectional survey method. The research subjects were orthodontists in West Java, Indonesia. The samples in this study were taken using total sampling technique. The samples were based on the sampling criteria below:-Inclusion criteria: an orthodontist from West Java, Indonesia, registered under The Indonesian Association of Orthodontist (IKORTI) and willing to participate in this study. The study material used was questionnaires that assessed the consistency in classifying subdivision malocclusion, the viewpoint of orthodontists in
West Java on how they interpret subdivision and the bases of their answer. The questionnaires were sent via email or posted in an envelope with self-addressed returned envelopes are included. The result were collected and managed.

\section{RESULTS}

A total of 80 respondents answered the questionnaires. The following are the results based on data analysis.

The table above describes the data consistency of orthodontists based on the number of correct answers. Of the 80 people who responses, the highest percentage of respondents $71.3 \%$ was consistent in classifying a subdivision malocclusion and only $6.3 \%$ of respondents fell under the group of inconsistent group.

The above table shows the number of respondents who supported specific opinion on the meaning of subdivision. Of the total respondents, the highest percentage of respondents $46.25 \%$ believed that subdivision referred to the Class II side of the arch and the lowest percentage of respondents $5 \%$ says subdivision referred to neither Class I nor Class II side of the arches.

The above table is a cross tabulation between the source of reference with side of subdivisions. Of 14 people who use Proffit as a reference, 4 of them stated that subdivision referred to Class I side, 6 of them stated that it referred to Class II side, 1 stated that it referred to

Table 1. The Consistency of Orthodontists in Classifying a Subdivision Malocclusion

\begin{tabular}{llll}
\hline No & Group & $\mathrm{f}$ & Percentage $\%$ \\
\hline 1 & Consistent & 57 & $71.3 \%$ \\
2 & Doubtful & 18 & $22.5 \%$ \\
3 & Inconsistent & 5 & $6.3 \%$ \\
\hline & Total & 80 & $100.0 \%$ \\
\hline
\end{tabular}

Table 2. Number of Respondents Who Support Specific Opinion on Meaning of Subdivision

\begin{tabular}{lcc}
\hline Side to which subdivision refers & Number of respondents & Percentage (\%) \\
\hline Class I & 20 & 25 \\
Class II & 37 & 46.25 \\
Neither & 4 & 5 \\
Both & 19 & 23.75 \\
\hline Total & 80 & 100.0 \\
\hline
\end{tabular}


Table 3. Cross Tabulation between References to the Side of Subdivision

\begin{tabular}{|c|c|c|c|c|c|c|}
\hline \multirow{2}{*}{ Source of reference } & \multicolumn{3}{|c|}{ Subdivision side } & \multirow[b]{2}{*}{ Neither } & \multirow[b]{2}{*}{ Both } & \multirow[t]{2}{*}{ Total } \\
\hline & & Class I & Class II & & & \\
\hline \multirow[t]{2}{*}{ Moyers } & $f$ & 4 & 4 & 1 & 4 & 13 \\
\hline & $\%$ & $5.0 \%$ & $5.0 \%$ & $1.3 \%$ & $5.0 \%$ & $16.3 \%$ \\
\hline \multirow[t]{2}{*}{ Profit } & $f$ & 4 & 6 & 1 & 3 & 14 \\
\hline & $\%$ & $5.0 \%$ & $7.5 \%$ & $1.3 \%$ & $3.8 \%$ & $17.5 \%$ \\
\hline \multirow[t]{2}{*}{ Salzmann } & $f$ & 1 & 6 & 0 & 3 & 10 \\
\hline & $\%$ & $1.3 \%$ & $7.5 \%$ & $0.0 \%$ & $3.8 \%$ & $12.5 \%$ \\
\hline Common & $f$ & 2 & 10 & 1 & 1 & 14 \\
\hline usage & $\%$ & $2.5 \%$ & $12.5 \%$ & $1.3 \%$ & $1.3 \%$ & $17.5 \%$ \\
\hline \multirow[t]{2}{*}{ Other } & $f$ & 6 & 9 & 1 & 5 & 21 \\
\hline & $\%$ & $7.5 \%$ & $11.3 \%$ & $1.3 \%$ & $6.3 \%$ & $26.3 \%$ \\
\hline \multirow{2}{*}{$\begin{array}{c}\text { Salzmann, } \\
\text { other }\end{array}$} & $f$ & 1 & 1 & 0 & 1 & 3 \\
\hline & $\%$ & $1.3 \%$ & $1.3 \%$ & $0.0 \%$ & $1.3 \%$ & $3.8 \%$ \\
\hline Moyers, & $f$ & 1 & 0 & 0 & 0 & 1 \\
\hline Profit, & $\%$ & $1.3 \%$ & $0.0 \%$ & $0.0 \%$ & $0.0 \%$ & $1.3 \%$ \\
\hline \multicolumn{7}{|l|}{ Salzmann } \\
\hline \multirow[t]{2}{*}{ Skipped } & $f$ & 1 & 2 & 0 & 0 & 3 \\
\hline & $\%$ & $1.3 \%$ & $2.5 \%$ & $0.0 \%$ & $0.0 \%$ & $3.8 \%$ \\
\hline Moyers & $f$ & 0 & 1 & 0 & 0 & 1 \\
\hline and Profit & $\%$ & $0.0 \%$ & $1.3 \%$ & $0.0 \%$ & $0.0 \%$ & $1.3 \%$ \\
\hline \multirow{2}{*}{ Total } & $f$ & 20 & 39 & 4 & 17 & 80 \\
\hline & $\%$ & $25.0 \%$ & $48.8 \%$ & $5.0 \%$ & $21.3 \%$ & $100.0 \%$ \\
\hline
\end{tabular}

neither side and 3 of them stated that it referred to both side. Of 14 people who stated that it was a common usage, 2 of them said that subdivision referred to Class I side, 10 of them stated the subdivision referred to Class II side, 1 of them stated that subdivision referred to neither side and 1 of them said that it referred to both side. 1 person used Moyers, Proffit and Salzmann as source of references stated that subdivision referred to Class I side and 1 person used Moyers and Proffit stated that subdivision referred to Class II side.

\section{DISCUSSION}

There were 80 responses of the 238 questionnaires sent, a $33.6 \%$ response rate. There are only 80 orthodontists responded to the questionnaires out of 238 respondents. This is because some orthodontists said they were out of town and even in overseas, some were very busy and choose not to participate in this research, some had personal problems and some said they had just undergo surgery and need time for to recover.

From the results it can be seen $22.5 \%$ falls in the category of doubtful and the percentage of inconsistent respondents account for $6.3 \%$. Even though most orthodontists are consistent, there is fairly high percentage of respondents that falls under the category of "doubtful" and "inconsistent". Angle refers subdivision as the unilateral occurrence of malocclusion, whereby one side is normal and the other side is abnormal without further detailed explanation. ${ }^{7}$ This shows an inadequacy in Angle classification.

The inadequacy above leads to confusion for respondent to classify a subdivision malocclusion. Some says it refers to normal side, and others claimed that it means the affected side. Some said they do not know the term subdivision. Table 2 shows the number of respondents who support specific opinion on the meaning of subdivision. Of the total 80 respondents, the highest percentage $46.25 \%$ believes that subdivision refers to the Class II side, followed by $25 \%$ believes it refers to the Class I side, $23.75 \%$ says that subdivision refers 
to both sides and only $5 \%$ stated neither sides.

Many respondents to the survey cited various sources as the bases of their viewpoint on the interpretation of subdivision. From the results, $16.3 \%$ out of 80 respondents says they referred to Moyers. "Subdivision- when the distoclussion occurs on one side of the dental arch only, the unilaterality is referred to as a subdivision of its division". 9 Moyers did not specify to which side unilateral referred or whether subdivision applied to the Class II or the Class I side. His writing restates that one side has maloccluded jaw relationship and the other side has normal jaw relationship. Orthodontists based their opinions in this uncertain statement and interpret Moyers to mean that subdivision reflected the Class II side and others perceived it to identify the Class I side, some said it represented neither side and some claimed it represented both sides (Table 3 ).

Meanwhile, from the total of 80 respondents, $12.5 \%$ said that they refer to Salzmann. Salzmann statement "Class II, Division 2, Subdivision. A Class II, Division 2, malocclusion in which the malocclusion is unilateral only"3 evokes differing perceptions between orthodontist. Again, Salzmann never articulated his perception on the exact meaning of subdivision. This arises a distinct form of thought. 1 respondent deemed that Salzmann support the beliefs that subdivision referred to Class I side, 6 respondents thought that his writings indicated the Class II side and 3 respondents said it referred to both side.

$17.5 \%$ turned to Proffit. He stated that "Occasionally the molar occlusion is Class II on one side and Class I on the other. Angle called this a Class II Subdivision right or left, depending on which was the Class II side". ${ }^{10} \mathrm{He}$ appears to directly support the assumption that subdivision refers to the Class II side; however he clearly bases his statement on Angle classification system, as acknowledge earlier, Angle never unequivocally said what subdivision means. Furthermore, Proffit did not directly state that subdivision is on the Class II side. Similarly, orthodontists perceived it in different ways from one another (Table 3).

Moreover, $17.5 \%$ out of the total respondents used their common usage as their bases on the interpretation of subdivision. This way of thinking equals to using their instinct to explain their theories without referring to valid sources.
In the analysis of these selected writings of Angle, Moyers, Salzmann and Proffit, none mention the true nature of the meaning of subdivision. However, recently there is a very clear statement regarding subdivision by Staley and Reske: "A Class II-1 Subdivision is written as follows: Class II Division 1 Subdivision right when the Class II molar relation is on the right side of the arches and Class II-1 Subdivision left when the molar relation is Class II on the left side of the arches". ${ }^{11}$ As things currently stand, this is the most accurate depiction, for it leaves no room for misinterpretation.

Orthodontics is a detailed-oriented specialty. It is important for the accurate diagnosis of patient. For the sake of uniformity and established an unassailable standard, every orthodontist must be able to consistently define and classify a malocclusion.

\section{CONCLUSION}

Most of orthodontists are consistent in classifying subdivision in a malocclusion by using Angle's Classification System, majority of the responded orthodontists stated that the meaning of subdivision itself refers to the abnormal side, and most of the responded orthodontists use Proffit and common usage as their source of references.

\section{REFERENCES}

1. Hassan, R.; and A. K. Rahimah. 2007. Occlusion, malocclusion and method of measurement-an overview. Archieves of Orofacial Sciences 2. Pp. 3-9.

2. Miguel-Neto, A. B.; C. Nishio; and J. N. Mucha. 2010. Agreement evaluation of a newly proposed system for malocclusion classification. Int. J. Odontostomat. 4(1):33-41.

3. Katz, M. I. 1992a. Angle classification revisited 1: is current use reliable? Am J Orthod Dentofacial Orthop. 102:173-9.

4. Katz, M. I. 1992b. Angle classification revisited 2: a modified Angle classification. Am J Orthod Dentofacial Orthop. 102:277-84.

5. Siegel, M. A. 2002. A matter of class: interpreting subdivision in a malocclusion. Am J Orthod Dentofac Orthop. 122:582-586.

6. Anderson, G. M. 1960. Practical Ortho- 
dontics. $\quad 9^{\text {th }}$ Edition. Mosby Company. St. Louis. Pp. 140-154.

7. Angle, E. H.1900. Treatment of Malocclusion of the Teeth and Fractures of the Maxillae. Angle's System. $6^{\text {th }}$ Edition. S. S. White Dental Manufacturing Company. Philadelphia. Pp. 34- 44.

8. Bishara, S. E. 2001. Textbook of Orthodontics. W. B. Saunders Company. United States of America. Pp. 98- 104.
9. Moyers, R. E. 1988. Handbook of Orthodontics. $4^{\text {th }}$ Edition. Year Book Medical Publisher, Inc. United States of America. Pp. 183- 195.

10. Proffit, W. R.; H. W. Fields; and D. M. Sarver. 2007. Contemporary Orthodontics. $4^{\text {th }}$ Edition. Elsevier. New Delhi. Pp. 218-229.

11. Staley, R. N.; and N. T. Reske. 2011. Essentials of Orthodontics: Diagnosis and Treatment. Blackwell Publishing Ltd. Pp. 3-10 